\title{
A instalação dos cursos de pós-graduação
} a onze de agosto.

\author{
Philomeno Joaquim da Costa \\ Catedrático de Direito Comercial na Faculdade
} de Direito da Universidade de São Paulo.

Instalam-se neste centésimo quadragésimo quarto Onze-de-agosto os cursos de pós-graduação em nível de mestrado e em nível de doutorado. Isto constitui a consagração de um novo tipo de altos estudos jurídicos neste casarão, que ostenta hoje-em-dia as galas de um palácio; os reposteiros de veludo sangüíneo deste salão nobre, aconchegando as suas solenidades, atestam um ambiente de atividades ascéticas. Aqui sempre se efetivam reuniões, que consagram a afirmação da vivência respeitosa do Direito.

Inicia-se um sistema diferente de formação de pesquisadores e de docentes das ciências jurídicas. Quis o nosso diretor que o seu começo ocorresse no mesmo dia do calendário, em que há 144 anos, se instituiam brasileiramente as duas primeiras faculdades de direito, uma de Olinda e presentemente no Recife, e outra na nossa cara Paulicéia, cuja garoa antiga o dinamismo pioneiro de bandeirantismo da sua gente tıansformou na fumaça densa, que polui o ar que nos circunda.

Quis o nosso diretor que a pós-graduação se iniciasse num Onze-de-agosto. Ele não fugia assim da condição de enfermo, de doente daquela moléstia contagiosa, incurável e fatal que ataca, agarra e perdura irremediàvelmente no coração

* Discurso proferido no salăo nobre a 11 de agostơ de 1971, na sessão comemorativa da Instalação dos Cursos de Pós-Graduação e da Fundação dos Cursos Jurídicos. 
de todos quantos são filhos desta nossa "velha sempre nova Academia". Esta doença é a palpitação cordial de carinho enternecido por esta nossa mãe espiritual. Somos felizes com os seus êxitos e padecemos com as suas penas. $\mathrm{O}$ aniversário natalício desta Casa tinha que ser relembrado filialmente. Inaugurando-se pois a pós-graduação nesta data, o Senhor Diretor encontrou simultaneamente a forma de dizermos mais uma vez do nosso mimo pela nossa Faculdade do Largo de São Francisco.

\section{O que é a pós-graduação no Direito?}

Ela pretende representar um sistema idôneo de estudos aprofundados das ciências jurídicas. A pós-graduação, importada do pragmatismo norte-americano, é uma combinação compulsória num primeiro momento de aulas teóricas e de trabalhos práticos e depois da apresentação de um estudo de fundo, concretizando o resultado dessa atividade científica.

Há duas maneiras de se expor a essência de uma pós-graduação no campo das ciências de conceito ou das ciências humanas. A primeira maneira pode ser chamada de exposição por contraste e é compreendida melhor por quem conhece o sistema antigo do doutorado. A segunda maneira de explicação, chamável de exposição descritiva, é intelígivel melhor por quem deseja saber aquilo em que consiste a pós-graduação sem vinculá-la ao que se fazia anteriormente com o doutorado.

Antigamente um estudioso apresentava no campo jurídico uma monografia conclusiva sôbre certa questão de direito e se propunha a sustentá-la perante mestres; era inabilitado ou aprovado conforme o êxito da sua sustentação; aliás já se exigia ultimamente que o doutorando desse demonstração horizontal um pouco maior dos seus conhecimentos presumidamente aprofundados; exigia-se dele que demonstrasse um certo preparo em duas disciplinas paralelas àquela a que pertencesse o assunto da tese.

Tinha-se destarte, em resumo, que as aplicações do espí- 
rito dependiam bastante do estudioso apenas; ele era no fundo um auto-didata; inexistia o encaminhamento racional das buscas sob a direção de um professor categorizado altamente; este deve ter um cabedal maior do que o catecúmeno, do que o aprendiz, do que o estudioso. $\mathrm{O}$ mestre era invocado pràticamente só para aprovar ou não aprovar aquilo que lhe era exibido no fim das pesquisas. Era este na essência o doutoramento do tipo europeu continental.

Agora todo o estudo se divide em duas grandes partes; uma consiste na obrigação do bacharel desenvolver um certo número mínimo de horas de aplicação sob controle dos mestres; a outra parte consiste no seu preparo de um trabalho de fôlego, em que revele a profundidade de suas pesquisas; a elaboração dêsse trabalho representa padronizadamente um outro número de horas de aplicação. A soma das horas sob controle do professor e das horas atribuidas à elaboração do trabalho de fundo perfaz a realização cronológica do curso. Haverá o coroamento obrigatório da defesa com êxito desse trabalho perante uma comissão examinadora de mestres. Entende-se então que o candidato realizou a pós-graduação.

E obviamente pós-graduação, porque os estudos só podem ser realizados pelos portadores de diploma de graduação. No campo das ciências humanas usava-se o nome de bacharel. Passa-se a usar a denominação de graduado, exemplificativamente, graduado em direito. Prosseguindo, já agora em regime de altos estudos, estes são posteriores à graduação. Daí compreensivamente a sua denominação de curso de depois-da-graduação, enunciado sintética ou aglutinadamente como a pós-graduação.

Esta opera-se em dois níveis, quer dizer-se, há o chamado mestrado e existe o denominado doutorado. Um distingue-se do outro apenas pela quantidade maior ou menor entre ambos de aplicação sob o controle dos mestres e para o preparo do trabalho de fundo. O mestrado consiste nos altos estudos, cujo tempo é a metade daqueles empregados no doutorado; 
no mestrado o coroamento da aplicação do candidato é a apresentação de uma dissertação; esta traduzirá uma análise de profundidade de assunto jurídico pertinente à disciplina, que foi escolhida como concentração do curso. O doutorado consiste nos altos estudos, cujo tempo de trabalho é o dobro daouele do mestrado. com a oferta final de uma tese; esta traduzirá uma investigacão jurídica inédita relativa à disciplina eleita como o miôlo do curso. Quase que a gente é levado a concluir nesta explicação incidente que o mestrado é a metade do doutorado; poder-se-ia enunciar a mesma idéia, expressando-se que o mestre é semi-doutor. Importa notar que mestrado não é uma primeira fase obrigatória do doutorado. Tanto se pode antes alcançar aquele e depois prosseguir-se no que se denominaria, nara compreensão mais fácil, da outra metade, como se pode pretender diretamente o doutorado, sem ter que fazer primeiramente o mestrado e se submeter às provas finais do exame de uma dissertação, trabalho típico e menos laborioso do que a tese.

A compreensão da mecânica da pós-graduação fica bem facilitada ao se saber que a diferença entre o mestrado e o doutorado tem sòmente duas distinções: a primeira consiste em que o mestrado tem uma integralização representada por um número de horas de estudos correspondente a cincoenta por cento daquele do doutorado; e a segunda distinção consiste em que no mestrado o candidato oferece no termo da sua aplicação apenas uma dissertação e não uma tese como no doutorado; a dissertação é necessàriamente um trabalho de pesquisa sem ineditismo, ao passo que a tese pressupõe uma pesquisa maior e representa uma construção nova proporcionada pelos altos estudos. Está claro que o grau de doutor em direito é hierarquicamente superior ao grau de mestre. $\mathrm{O}$ mestre em direito poderá apenas conquistar como professor uma disciplina em faculdade de direito reconhecida e ele será no máximo professor assistente em faculdade de direito oficial. $\mathrm{O}$ doutor em direito tem a perspectiva de prosseguir na carreira docente e na pesquisa. 
A pós-graduação tem nos seus dois níveis um modo típico de marcação do tempo de estudos. Já se viu que o candidato deve frequientar e desenvolver um certo número de horas de aplicacão sob o controle dos mestres. Está se dando o nome a isto de "escolaridade"; são as aulas formais ou' teóricas e são as leituras obrigatórias. os debates e seminários. E iá se viu que o candidato deve elaborar também um trabalho final de profundidade. Dá-se-lhe o nome de "elaboração da dissertação ou tese" conforme se trate respectivamente de mestrado ou de doutorado. Há uma regra de contagem de horas de estudo, provinda de nortaria do magnífico Reitor da Universidade, de n. ${ }^{\circ}$ GR 885 , de 25 de agosto de 1969, aue nor seu turno é a aplicacão do que determinon pioneiramente 0 Parecer 77/69 de 11 de fevereiro de 1969 do egrégio ConseTho Federal de Educacão. Essa regra determina que o mestrado e aue o doutorado serão feitos com a realização de um certo número mínimo de horas de atividades escolares. Cada doze horas forma uma denominada Unidade de Crédito. $O$ mestrado deverá concretizar pelo menos 120 dessas unidades ou sejam 1.440 horas de aplicacão efetiva ou presumida; e o doutorado compreenderá o dobro. Isto quer significar que a pós-graduação em nível de mestrado necessita de representar 120 Unidades de Crédito e o doutorado deve consistir em 240 Unidades de Crédito. Só depois de completálas e ser aprovado num exame final, chamado de "exame de qualificação", o candidato poderá pretender defender o seu trabalhomestre, para obter o grau desejado.

Como se declarou, a elaboração da dissertação ou da tese atribui rígida ou fixadamente ao candidato um certo número de Unidades de Crédito, quer êle tenha consumido particularmente um número maior ou menor de horas de pesquisas e de elaboração. No mestrado o candidato conta em seu prol 55 Unidades e no doutorado êle computa 115 dessas Unidades.

Segue-se portanto que no mestrado a contagem de 120 
Unidades é diminuída pela dissertação de 55 delas. Restam 65 Unidades; no doutorado essa contagem é de 240 Unidades diminuída pela tese de 115 delas. Restam 125 Unidades.

Estes saldos, usando-se esse termo apenas para efeito de explicação, devem ser preenchidos com a freqüência e exames de aproveitamento num certo número de disciplinas, todas de duração semestral. Referindo-se à mesma coisa por um ângulo diferente, os candidatos devem freqüentar cadeiras, chamadas agora obrigatoriamente de disciplinas, em gue cada uma atribui 8 Unidades de Crédito em caso de êxito. Quando um candidato completar assim 55 dessas Unidades, como aspirante ao mestrado, êle pode cuidar de oferecer a sua dissertação, em cuja elaboração poderá ter-se adiantado bastante. Quando um candidato completar com êxito 125 Unidades de Crédito, como aspirante ao doutorado, êle poderá cuidar de oferecer igualmente a sua tese, em cuja elaboração se imagina se tenha dedicado. Tanto a dissertação como a tese são elaboradas sob a direção do orientador; daí a necessidade da sua eleição inicial com a matrícula. É a denominada área de concentração; as demais disciplinas integrantes dos altos estudos figuram como a chamada área do domínio conexo desse candidato.

Tendo-se então em consideração as Unidades de Crédito, que cada um deve contar, pode complementar-se a explicação com o dizer-se que o candidato deve seguir e obter aprovação em tantas disciplinas que, multiplicadas por 8 , alcancem o número mínimo de Unidades de Crédito que perfaça o nível da pós-graduação desejada. No mestrado esse mínimo residual é de 65 Unidades ou, recordando-se, são 120 Unidades totais subtraídas das 55 Unidades atribuídas padronizadamente à elaboração da dissertação.

No mestrado o candidato deve alcançar êxito em 9 disciplinas, porque 8 só ensejam 64 Unidades, isto é 1 a menos do mínimo. Fêz-se de propósito. Há candidatos que podem beneficiar-se excepcionalmente de contagem de Unidades, 
porque tenham outros cursos universitários ou desenvolvido trabalhos especiais fora da Universidade. As disciplinas cursáveis poderão baixar excepcionalmente. Então o candidato cursará normalmente 9 disciplinas. Tem que inscrever-se no mínimo em 3 por semestre. Serão 3 semestres. Se êle inscrever-se em número maior, com a compatibilidade de horário, apressará a sua escolaridade.

No doutorado o candidato deverá semelhantemente ter êxito em 18 disciplinas, porque o mínimo da sua escolaridade é de 125 Unidades, vale dizer-se o total de 240 delas subtraídas das 115 atribuídas arbitrariamente à elaboração da sua tese. Inscrevendo-se por semestre em 3 disciplinas mínimas, dispenderá 6 semestres, mas se ele seguir, como todos poderão, um número maior dentro da compatibilidade de horários, apressará também a sua chamada escolaridade.

Cada professor dá suas aulas teóricas e dirigirá direta ou indiretamente os seminários da sua disciplina. Ele lecionará simultaneamente os candidatos ao mestrado e ao doutorado; em relação porém aos candidatos, que o elegeram (com a sua prévia aquiescência) para orientador, ele deverá dirigir pessoalmente as investigações, que culminarão na elaboração da dissertação ou da tese. Para estes candidatos a disciplina ministrada representa a área de concentração, a insinuar claramente que é nela que se sedimentam os altos estudos do candidato.

Eis a essência da mecânica da pós-graduação. A Faculdade de Direito dividiu-se em 10 departamentos. Com exceção daquele de Medicina Forense, todos os nove mais conseguiram formar a denominada massa crítica, oferecendo cursos de pós-graduação. Os Departamentos de Filosofia e Teoria Geral do Direito, de Direito Civil, de Direito Comercial, de Direito Processual e de Direito Econômico e Financeiro, tendo-se em vista o número dos docentes respectivos e da quantidade das disciplinas afins, oferecem a pós graduação em nível de mestrado e de doutorado. Os Departamentos 
de Direito do Trabalho, de Direito Penal, de Direito do Estado e de Direito Internacional oferecem a pós-graduação em nível de mestrado. É lícito prever-se que já no primeiro semestre de 1972 possam também estes quatro departamentos oferecerem indispensavelmente esses altos estudos na sua expressão mais significativa. E preciso não se esquecer de que é absolutamente essencial na pós graduação que cada candidato tenha à sua escolha um número de disciplinas bem maior do que aquelas que deverá cursar. E a já asseverada massa crítica. A falta de um número maior de mestres - que não pode cada um ministrar mais do que três disciplinas - e a existência de número limitado de outras afins, correlatas ou de área de domínio conexo, forçaram a que os órgãos da Universidade, controladores do estabelecimento da pós graduação, não admitissem na verdade o doutorado generalizado nesta $\mathrm{Fa}$ culdade.

Oxalá que os esforços dispendidos anonimamente possam frutificar e surja mesmo uma pós-graduação real. Oxalá que este centésimo, quadragésimo quarto Onze-de-agosto, represente o marco de fixação de uma autenticidade jurídicacientífica. Oxalá que o nosso diretor possa inscrever em baixo relevo rubro dentro em breve, sobre os portais principais externos deste nosso antigo convento, voltadas para o bulicioso Largo de São Francisco, as palavras: "Escola de Altos Estudos Jurídicos" Poderemos ir honestamente para o majestoso conjunto universitário do Butantã com os cursos de graduação. Ficaremos eternamente, por nós e pelos nossos pósteros, com a pós graduação neste casarão, que é patrimônio sedimentado das galas do mais puro e indobrável brasileirismo. 